\title{
Fundamentos teóricos para a formação de professores: a prática reflexiva
}

Magdalena Viggiani Jalbut é psicóloga, especialista em psicoterapia, mestra em Educação e Currículo pela Pontifícia Universidade Católica de São Paulo, autora de livros didáticos e artigos de educação. É coordenadora dos cursos de graduação em Pedagogia e pós-graduação do ISE Vera Cruz e de extensão do Centro de Estudos Educacionais Vera Cruz.

Contato: magdalena@veracruz.edu.br

\section{Resumo}

Este artigo traz reflexões sobre a formação do professor como prático reflexivo, tendo como referência teórica a concepção da racionalidade prática de Schön $(2000 ; 1995 ; 1983)$, com contribuições acerca do ofício docente de Zeichner (1993), Pérez Gómez (1995), Claxton (2005), Canário (2006), Nóvoa (1995) e Giroux (1997). Fazendo contraposição ao modelo da racionalidade técnica, aponta o ensino das artes, que considera o aprender fazendo, como modelo de racionalidade prática no qual alunos e professores têm a oportunidade de refletir criticamente sobre a sua atuação.

Palavras-chave: formação de professores, prática reflexiva, identidade profissional.

\section{Abstract}

This article presents insights on the training of teachers as reflective practitioners. Its theoretical reference is provided by studies conducted by Schön $(2000 ; 1995 ; 1983)$ on the conception of practical rationality, along with contributions on the teacher profession from Zeichner (1993), Pérez Gómez (1995), Claxton (2005), Canário (2006), Nóvoa (1995) and Giroux (1997). In counterpoint to the model of technical rationality, it points to the teaching of arts - considered knowledge-in-action - as the model of practical rationality that gives students and teachers the opportunity to reflect critically about their roles.

Keywords: teacher training, reflective practice, professional identity. 
Este artigo desenvolve concepções sobre a formação de professores e o papel da prática profissional no trabalho docente, na concepção de formação da racionalidade prática, considerando Schön $(2000 ; 1995 ; 1983)$ como um dos importantes autores que propõem a formação do professor como prático reflexivo e os practicum como modelos de formação. Zeichner (1993) denominou esse modelo de prática reflexiva. Tem ainda como sustentação Feldmann (2004), Libâneo (2004) e Mizukami (2003), na concepção de projetos de formação de professores no Brasil.

Este artigo tem como pressupostos a ideia do professor como o sujeito de sua formação e a concepção da racionalidade prática, trabalhando a dimensão humana e o desenvolvimento da pessoa.

O pensamento de Nóvoa (1995) fala de produzir a vida do professor, da construção da identidade profissional e de um trabalho de reflexão crítica sobre as práticas. Pérez Gómez (1995) trata do lugar da construção do pensamento prático do professor em sua formação. Canário (2006), por sua vez, contribui para esclarecer a relação complexa entre a formação inicial de professores e o exercício profissional nas escolas, que se beneficia de um conjunto de "saberes tácitos". Esse autor propõe, como estratégia formativa, a otimização do potencial nos contextos de trabalho, chamando-a de uma "formação centrada na escola", o que nos remete à questão da identidade profissional do professor.

0 tema da identidade profissional docente, por sua vez, remete-nos aos saberes e competências necessários à profissão. Segundo Libâneo e Sacristán (2004), trata-se do desenvolvimento autônomo e emancipatório do professor, em uma prática reflexiva.

0 pensamento de Giroux (1997) sobre politizar-se a noção de escolarização aponta o papel dos professores como intelectuais transformadores, na visão de uma sociedade emancipadora.

\section{Formação de professores}

A formação de professores entendida como um continuum, ou seja, como um processo de desenvolvimento que acontece por toda a vida (Mizukami, 2003), amplia a concepção de formação 
considerada como conjunto de momentos formais na formação inicial ou como sinônimo de eventos com caráter de reciclagem ou capacitação, que prevaleceram até há pouco na história da Educação. Este modelo se apoia na cultura de conhecimentos teóricos para aplicação posterior na prática, o que o torna coerente com o pensamento da racionalidade técnica, segundo o qual a atividade profissional envolve problemas de caráter instrumental que exigem aplicação de teorias para resolvê-los. A formação profissional, no âmbito desta concepção, é um processo de preparação que permite compreender o funcionamento das regras e técnicas da realidade da sala de aula e desenvolver as competências profissionais exigidas pela sua aplicação eficaz (Pérez Gómez, 1995). 0 professor é entendido como um especialista que aplica as regras do conhecimento científico às situações idealizadas para a sala de aula. Parece que a reflexão não faz parte do curso de formação, nessa concepção, desconsiderando aspectos do contexto em que as práticas se inserem.

No entanto, este artigo tem como pressuposto que as questões da prática não se constituem em problemas meramente instrumentais, que podem ser resolvidos pela aplicação de regras. A realidade educacional e as situações de ensino envolvem outros aspectos além dos instrumentais, pois são incertas, únicas, singulares, complexas, e não há uma teoria científica única que possa ser utilizada.

Ao tratar da complexidade dos fenômenos educativos, encaminha-se para ultrapassar o modelo de formação baseado na racionalidade técnica, que forma o professor como especialista, desconsiderando a formação mais complexa, a do cidadão com compromisso político, com valores éticos e morais, o que pressupõe o desenvolvimento da pessoa, tornando-a capaz de conviver com mudanças e incertezas.

Os autores citados refletiram sobre o tema de formação de professores em relação ao ensino, com enfoque reflexivo sobre a prática. Este artigo destaca o papel do professor como profissional que se confronta com situações singulares, tentando superar a relação linear e mecânica entre conhecimento técnico-científico e prática da sala de aula.

Schön (1995) é considerado um dos autores importantes que tratam da reflexão nas reformas educacionais ocorridas nas décadas de 1980 e 1990 em diversos países. Considera que o conceito de reflexão envolve: 
- O conhecimento-na-ação, que é o conhecimento técnico que se manifesta no saber fazer e o componente inteligente que o orienta. 0 saber fazer e saber explicar o que se faz são capacidades diferentes, mas complementares.

- A reflexão-na-ação, que considera não só o saber escolar, mas as emoções relacionadas à confusão e à incerteza. Um professor reflexivo deve considerar a confusão do aluno e a própria. 0 professor deve aprender com os próprios erros. Pensamos sobre a atividade da prática, ao mesmo tempo que a realizamos. É um diálogo com a situação e sobre a interação.

Segundo Pérez Gómez (1995), a reflexão-na-ação é um conhecimento de segunda ordem ou metaconhecimento-na-ação, pressionado pelo espaço, tempo, solicitações psicológicas e sociais. É a reflexão sem o distanciamento da análise racional, mas com a riqueza do momento, com suas dificuldades e limitações. A reflexãona-ação é um rico processo na formação do profissional prático, um instrumento de aprendizagem para o profissional flexível.

- Reflexão-sobre-a-ação é aquela que se realiza depois da ação. À medida que o professor se distancia da situação, é possível refletir sobre a reflexão-na-ação por meio da observação e da descrição em palavras do ocorrido.

0 professor liberto dos condicionamentos da prática, segundo Pérez Gómez (1995), pode analisar a situação a posteriori, utilizando o seu conhecimento para a descrição, análise e avaliação. A reflexão-sobre-a-ação supõe um conhecimento de terceira ordem, analisando o conhecimento-na-ação e a reflexão da situação na ação.

Esses três aspectos se complementam, constituindo o pensamento prático do professor, e garantem uma intervenção racional, partindo do pressuposto de que o professor, além de reflexivo, tem que ser propositivo e empreendedor.

0 conceito de reflexão das situações de ensino originou o termo prática reflexiva, que foi objeto de estudo de autores como Zeichner (1993), o qual referenda John Dewey, que no início do século XX fez a distinção entre ato humano reflexivo e rotina.

Empregar o conceito de reflexão não significa que o professor refletirá profissionalmente sobre tudo, pois haverá sempre rotina em sua prática. 0 professor precisa buscar o equilíbrio entre a 
reflexão e a rotina, decidindo conscientemente seu caminho, construindo a própria prática de forma reflexiva.

Zeichner (1993) aponta a direção para que os professores desenvolvam suas teorias práticas à medida que refletem durante a ação acerca dela, de seu ensino e das condições sociais de suas práticas pedagógicas. Isso propiciará que, das práticas, se desenvolvam outras teorias, e assim sucessivamente.

\section{Da racionalidade técnica à racionalidade prática}

Nos cursos de formação de professores, considerando-se o pressuposto da racionalidade técnica, o ensino dos conteúdos sobrepõe-se às reflexões de questões da prática presente no cotidiano do professor.

Schön (1995) aponta o conflito entre o saber escolar e a reflexão-na-ação dos professores e alunos em formação e, para avançar, propõe a formação do professor como prático reflexivo, buscando a superação da relação mecânica entre conhecimento técnico e a prática da sala de aula. Aponta o modelo do ensino das artes, que considera o aprender, fazendo a prática. Os alunos que começam passam pelo experimento, pelo erro, pela consciência do erro e pelo trabalho de refazer seu percurso. Nesse modelo de formação, o futuro professor tem oportunidade de refletir sobre os problemas de sua atuação, estabelecendo um diálog’o com a situação complexa.

Segundo Schön (1995), as instituições de Educação Artística ateliês de pintura, escultura etc. -baseiam-se numa concepção de saber escolar diferente do praticado nas universidades. Contêm as características de um practicum reflexivo, implicando um aprender fazendo, em que os alunos começam a praticar mesmo antes de compreender racionalmente o que estão fazendo.

Segundo Schön (2000), o practicum é um mundo virtual que representa o mundo real da prática e permite fazer experiências, cometer erros, se conscientizar e tentar de outra forma. No practicum reflexivo os alunos praticam na presença de um tutor/ supervisor e uma relação se estabelece por meio de palavras e ações, e o tutor/supervisor também pode agir e pedir que os alunos em formação o imitem.

A aprendizagem de novas competências depende da imitação que apreende o essencial, considerada, nesse contexto, uma ação 
criativa. 0 diálogo por meio de ações e palavras, demonstração e imitação, constrói significados entre o aluno em formação e o tutor/supervisor.

Segundo Zeichner (1993), para que isso seja possível, o practicum tem uma conotação investigativa que toma como ponto de partida a reflexão dos alunos em formação sobre a sua própria experiência.

Mas o que significa formar um professor para que ele se torne mais apto a refletir na e sobre a prática?

De acordo com Schön (1995), as experiências de formação em Educação Artística trazem as características de um practicum reflexivo, que implicam um tipo de aprender fazendo, no qual os alunos começam a praticar juntos com outros na mesma situação. No practicum reflexivo, os alunos praticam na presença de um tutor, e ele pode fazer demonstrações e pedir aos alunos para imitá-lo, o que, no ambiente educacional inovador, pode ser considerado contra a construção da autonomia do aluno.

Os practicum reflexivos podem acontecer para os professores em diferentes momentos de formação e de prática profissional, ajudando-os a refletir sobre o que fazem com os alunos, por meio dos dados observáveis. A observação direta, registrada com descrição de ações, pode produzir um choque educacional, à medida que os professores percebem que atuam de forma diferente daquilo que falam. Um obstáculo inicial à reflexão na e sobre a prática é a epistemologia da escola e a distância que ocorre entre o saber escolar e a compreensão dos alunos e entre o saber escolar e o modo espontâneo como os professores vêem o ensino. Na formação de professores, as duas dificuldades para a introdução de um practicum reflexivo são a epistemologia da graduação e o seu currículo normativo, no qual primeiro se ensinam os princípios das ciências, depois a sua aplicação e, por fim, o practicum que aplica os princípios da ciência. Mas para o practicum ter utilidade deve envolver outros conhecimentos, diferentes do escolar.

Schön (1995) estimula os practicum na formação inicial, nos espaços de supervisão e na formação continuada. 0 modelo de uma prática reflexiva está em conflito com as concepções da racionalidade técnica, que vivem um ressurgimento nos cursos de graduação, de uma forma geral. Esse conflito de epistemologias promove riscos em relação à capacidade de usar nosso lado mais humano e criativo. 
A abordagem do professor como sujeito de sua formação considera a concepção da racionalidade prática, que trabalha o desenvolvimento humano, envolvendo a dimensão pessoal.

A relação entre educação e contemporaneidade enfoca os temas do trabalho e a formação do indivíduo, não só como instrumentalização técnica, mas também como desenvolvimento pessoal, em sua formação de cidadão.

\section{Pensamento prático do professor}

0 professor enfrenta questões que exigem tratamento específico, ligado ao contexto com o qual se depara e à sua história de vida. 0 conhecimento prático é a capacidade do professor de manejar a complexidade e resolver problemas práticos, e é analisado por Schön (1983) como processo de reflexão-na-ação ou como diálogo reflexivo com a situação problemática concreta.

A reflexão implica na imersão consciente do homem no mundo da experiência. 0 conhecimento teórico só pode ser instrumento de reflexão se for integrado ao esquema de pensamentos ativados pelo indivíduo ao interpretar a realidade. Parte-se da análise das práticas dos professores, quando enfrentam questões complexas do cotidiano escolar, para considerar como utilizam o conhecimento científico e como fazem uso dos instrumentos conhecidos. A reflexão é um conhecimento contaminado pela experiência do indivíduo.

Segundo Pérez Gómez (1995), o pensamento prático do professor é de importância central nos programas de formação de professores para compreender os processos de ensino e aprendizagem e para promover a qualidade do ensino.

Considerar a construção do pensamento prático do professor como importante para sua formação implica em pensar no papel deste como profissional e nos princípios, conhecimentos e métodos do curso de formação. A nova epistemologia da prática redireciona a função do educador como profissional e, consequentemente, há uma mudança na concepção de formação.

0 modelo técnico de formação de professores estabelece uma hierarquia entre o conhecimento científico e as técnicas da prática. 0 abismo entre a teoria e a prática é o que mais propicia o fracasso dos cursos de formação na concepção tecnicista. 
A prática, como aplicação no contexto escolar das normas e técnicas do conhecimento científico, é considerada o cenário adequado ao desenvolvimento das competências, capacidades e atitudes profissionais do profissional de educação.

Nos modelos de formação de professores na concepção da epistemología da prática, os professores são preparados para a reflexão artística das situações do cotidiano. No exercício profissional, o diálogo com a prática mostra aspectos ocultos da realidade formada na relação psicossocial da sala de aula, não havendo uma solução única para cada problema. Explicita, portanto, uma nova realidade, que obriga a ultrapassar as regras, teorias e procedimentos conhecidos. 0 profissional reflexivo edifica o seu próprio conhecimento, incorporando e ampliando o conhecimento da racionalidade técnica.

A prática é o lugar de construção do pensamento concreto do professor, um espaço efetivo em que o aluno atua, reflete, sem a total responsabilidade sobre os efeitos de suas ações. 0 eixo do currículo de formação promove o desenvolvimento das capacidades e competências do conhecimento-na-ação, das capacidades, conhecimentos e atitudes da reflexão-na-ação e da reflexão-sobre-a-ação e sobre-a-reflexão-na-ação, que não dependem da assimilação do conhecimento acadêmico, mas daquele produzido em diálogo com a situação real.

A prática adquire um lugar central no currículo de formação, como lugar de aprendizagem e de construção do pensamento prático do professor. Entendida nessa perspectiva é colocada como núcleo em torno do qual gira o currículo acadêmico, sendo diferente da prática colocada ao final do currículo.

A prática escolar, como objeto de reflexão, constitui um campo de conhecimento que é específico do professor. 0 exercício de reflexão sobre a prática, tematizando-a em seus múltiplos aspectos, de forma organizada e compartilhada, faz parte das estratégias de formação e está vinculado à concepção de professor reflexivo, que toma a sua atuação como objeto de reflexão.

$\mathrm{Na}$ atuação nas escolas, alunos em formação se experimentam como professores e podem desenvolver a competência de atuar em situações contextualizadas, construindo instrumentos de intervenção pedagógica. 0 professor que já assumiu sua classe pode tê-la como referência. Aprende-se a exercer um trabalho, aprende-se a ser professor. 
Pérez Gómez (1995) coloca que o pensamento prático do professor não pode ser ensinado, mas pode ser aprendido. Por meio da ação e refletindo na e sobre a ação, desenvolve-se o pensamento prático do aluno em formação, através da mediação do professor-supervisor.

Em relação ao desenvolvimento pessoal, Nóvoa (1995) refere-se a produzir a vida do professor, permitindo que este se aproprie do seu processo de formação, que se realiza por meio da construção permanente de uma identidade pessoal, que é também identidade profissional, e de um trabalho de reflexão crítica sobre as práticas. Dessa forma, o docente dá sentido à sua trajetória.

0 movimento sugerido por Schön (1995), "conhecimentona-ação, reflexão-na-ação e reflexão-sobre-a-ação e sobre-areflexão-na-ação", tem sentido no desenvolvimento pessoal dos professores, quando cada um produz a sua vida e sua profissão.

Schön propõe uma epistemologia da prática que lida com o conhecimento profissional, tendo como referência a competência da prática, especialmente a reflexão-na-ação: "Pensar o que fazem, enquanto fazem", em situações de incerteza.

Nessa perspectiva, assume-se que não existe um conhecimento profissional que teria apenas uma solução. 0 profissional competente atua refletindo durante a ação, experimentando-se por meio do diálogo que estabelece com a realidade, construindo estratégias de ação e novos modos de enfrentar as questões da prática. 0 profissional reflexivo, comparado ao artista, constrói o seu conhecimento profissional por meio da prática, que supera 0 conhecimento técnico, que tem, sem dúvida, valor instrumental.

0 pensamento de Nóvoa, que fala de produzir a vida do professor, destacando a pessoa e os saberes da experiência, aponta para elementos que podem promover modificações pessoais no professor-profissional. Aprende-se a ser profissional, aprende-se a ser professor.

0 professor não é um técnico especialista que aplica o conhecimento científico às situações da escola e da sala de aula. A formação do aluno é complexa e envolve objetivos profissionalizantes, tratando também do seu desenvolvimento pessoal.

As transformações só se efetivarão se o professor se conscientizar da sua prática. A supervisão se constituiu no espaço prioritariamente voltado para a construção da autonomia de sua 
atuação profissional, na qual a reflexão sobre a prática traduz a concepção de que esta é analisada à luz das teorias.

Segundo Canário (2006), a prática profissional não é só o elemento-chave no currículo de formação de professores, como também seu elemento estruturante. Ela se apoia a partir de um eixo metodológico de pesquisa que tem como referência as situações do trabalho. É importante que a organização da prática profissional se faça com a organização escolar e não apenas com professores isolados, que pretendem cooperar individualmente. É um processo de formação inicial e contínua, envolvendo alunos e professores que os recebem nos estágios, assim como os professores do curso de formação, e constitui um processo de intervenção nas escolas, podendo ser um elemento de transformação da vida nesses locais.

Os professores aprendem o essencial de sua profissão na escola, nela ocorrendo a construção de sua identidade. A prática profissional beneficia-se de um conjunto de "saberes tácitos", que segundo Schön, em Canário (2006), correspondem a "um saber escondido no agir profissional". Dessa forma, a estratégia formativa é a otimização do potencial nos contextos de trabalho, chamada de "formação centrada na escola".

Um outro aspecto importante é a identidade da pessoa. Schön, em Nóvoa (1995), coloca que o processo de reflexão-na-ação envolve uma série de momentos combinados: primeiro há o momento de surpresa, quando o professor se surpreende com o que o aluno faz; depois, o educador pensa sobre o fato e procura compreender a razão de sua surpresa; no terceiro momento, reformula o problema suscitado pela situação; no quarto age, testando a sua nova hipótese. Esse processo de reflexão-na-ação não exige o uso de palavras. Também é possível analisar retrospectivamente e refletir sobre a reflexão-na-ação após a aula, pensando no que aconteceu, no que se observou, no significado dado e na perspectiva de outros sentidos. Os alunos em formação podem saber a teoria, mas não significa que dominem a ação.

Outra dimensão da reflexão-na-ação consiste no que Israel Scheffler, em Nóvoa (1995), chamou de emoções cognitivas, que têm a ver com confusão e incerteza. A aprendizagem envolve essa fase. Um professor reflexivo deve reconhecer e encorajar a incerteza dos alunos, assim como as suas próprias confusões, para poder reconhecer o problema que necessita de explicação.

0 desenvolvimento de uma prática reflexiva eficaz tem que estar inserida no contexto escolar. Fazer da escola um lugar no qual seja 
possível ouvir os alunos e aprender a ouvi-los são atitudes que devem estar associadas.

Tendo como pressuposto que a formação de professores é uma modalidade de formação profissional, Canário (2006) contribui para esclarecer a relação complexa entre formação inicial de professores e exercício profissional nas escolas. Coloca que a formação deve produzir a identidade profissional ligada ao ofício do professor. Ele privilegia a formação no contexto do trabalho, destacando, dessa forma, o exercício profissional e a identidade docente.

Passou-se da relação de previsibilidade entre formação de professores e mundo do trabalho para outra, de incerteza. $\mathrm{Na}$ relação de previsibilidade, que nunca foi total, a formação seria, supostamente, um processo cumulativo, linear, estabelecendo, como desempenho profissional, uma relação funcional e de adaptação. Essa relação é substituída por uma relação de incerteza.

As capacidades para mobilizar no momento certo as respostas certas, aprendidas na formação tecnicista, são substituídas pelas capacidades de análise, que podem equacionar problemas complexos e marcados pela incerteza.

0 modelo "fordista" da produção de massa, da economia em escala, é substituído por organizações mais flexíveis, menos hierarquizadas, destacando a organização em rede, que valoriza as modalidades de trabalho coletivo. A formação passa a se orientar para o trabalho de equipe, e deixa-se de pensar nela, quase exclusivamente, como capacitação individual.

As escolas, assim como as organizações de trabalho, tendem a multiplicar os processos de produção de conhecimento sobre seu funcionamento. Assim, poderão transformar-se em organizações capazes de aprender, e os docentes, em reconhecidos integrantes de uma comunidade de aprendizagem.

0 tema da identidade profissional remete-nos aos saberes e competências exigidos para a profissão. Libâneo (2004) destaca que os saberes são conhecimentos teóricos e práticos da profissão, e as competências são as capacidades, habilidades, atitudes relacionadas a esses saberes, que permitem o exercício da profissão.

Libâneo (2004) entende que a competência profissional de professores envolve o uso de conhecimentos e capacidades para fazer um trabalho, lidar com uma situação ou resolver um 
problema. A competência está ligada a um modo adequado de pôr em ação conhecimentos, supondo seu domínio. Na perspectiva sociocrítica, a competência é entendida como formação integral, em que os profissionais desenvolvem capacidades subjetivas (intelectuais, físicas, sociais, estéticas, éticas e profissionais), visando a unidade entre capacidades intelectuais e práticas. Envolve o método de análise reflexiva em que as pessoas avaliam suas atividades, desenvolvem competências na ação e incorporam novos saberes.

Na perspectiva de reflexão da prática, os autores Sacristán e Pérez Gómez (2000) apontam três aspectos fundamentais para os programas de formação de professor:

- Aquisição de uma bagagem cultural de orientação política e social, enfatizando as disciplinas humanas como eixo central dos conteúdos do curso: História, Políticas Públicas etc.

- Desenvolvimento de capacidades de reflexão crítica sobre a prática.

- Desenvolvimento de atitudes que exigem o compromisso político do professor, como intelectual transformador na aula, na escola, no contexto social, com atitude de experimentação, generosidade e colaboração.

Dessa forma, a prática profissional do professor é considerada intelectual e autônoma, por meio de um processo de ação e reflexão cooperativa para facilitar a compreensão dos alunos e, também, para desenvolver a sua compreensão ao refletir sobre sua ação.

A prática profissional é a questão central dos projetos de formação, nos quais o aluno em formação aprende em um contexto de referências, sendo o sujeito da própria aprendizagem.

\footnotetext{
Propomos um modelo de formação para o educador profissional e reflexivo que reimprima essa nova concepção, em que o processo dialético entre teoria e prática seja substituído por um ir-e-vir entre prática-teoriaprática, sendo o professor capaz de analisá-las, resolver problemas e criar estratégias para uma ação autônoma e responsável (Feldmann et al. 2004, p. 156).
}

0 pensamento de Giroux (1997), sobre politizar-se a noção de escolarização, aponta o papel dos educadores: o papel de intelectuais transformadores. Combina reflexão e ação para a 
formação dos alunos, para que analisem o mundo criticamente e possam transformá-lo. Destaca que os professores precisam compreender como as subjetividades são produzidas e reguladas por meio de formas sociais historicamente produzidas e como incorporam interesses particulares. Concebe as escolas como esferas públicas democráticas, nas quais professores e alunos trabalham para construir uma visão emancipadora da sociedade. Pergunta como podemos tornar a escolarização significativa, de forma a torná-la crítica e como torná-la crítica, de forma a torná-la emancipadora.

A Educação não é um empreendimento neutro, e o educador está envolvido em um ato político de forma consciente ou não. À medida que tem consciência do seu papel político-pedagógico, pode optar por orientar suas ações por uma concepção democrática, crítica e formar alunos que pensem e atuem criticamente.

0 pensamento de Giroux, concebendo as escolas como esferas públicas democráticas com uma visão emancipadora da sociedade, nos ilumina para acreditar na possibilidade de um mundo melhor.

Segundo Feldmann (2004), o educador do século XXI precisa mudar sua postura, abandonando a figura de um falso dono do saber ou de um técnico para ser o mediador entre o conhecimento e as necessidades dos alunos, objetivando ampliar e diversificar formas de interagir e compartilhar experiências em novos tempos e espaços.

Vivemos em um mundo de incertezas, de provisoriedade, em uma sociedade complexa em que as transformações ocorrem rapidamente. Há uma instabilidade geral e nesse contexto é prática comum deslegitimar e desqualificar instituições como a escola e seu saber docente.

A construção de uma Educação mais justa e democrática, comprometida com a formação ampla do cidadão, recupera o lugar da escola como instituição social. A importância da função docente é indispensável à sociedade, e a tarefa de formar professores conscientes de sua responsabilidade passa, necessariamente, por formá-los visando a se tornarem reflexivos de sua própria prática.

\section{Inovação na formação de professores}

Para discutir a temática da inovação na Educação, e mais especificamente no contexto da formação de professores, é necessário direcionar as investigações para o significado de inovação em uma dimensão geral. 
A inovação compreende um conjunto de ações planejadas com o propósito de modificar uma estrutura, ideia, pensamento ou método dominante em um contexto histórico, social, político e ideologicamente determinado e específico. Nesse sentido, entende-se que a inovação, por estar inserida num cenário mais abrangente, é indissociável das relações de poder e resistência que definem uma conjuntura social, exigindo dos pesquisadores inseridos nessa temática o respeito àquilo que foi considerado inovação em períodos anteriores e ao contexto no qual esse conjunto de ações foi estabelecido.

Por ser planejada, entende-se que a inovação resulta de uma prática intencional e política, que surge a partir da constatação de um problema, de um desconforto do sujeito diante de alguma situação na qual tenha se envolvido diretamente ou em função de novas necessidades e exigências evidenciadas na estrutura da sociedade na qual está inserido.

Claxton (2005), ao sugerir que o processo de inovação vem acompanhado de insegurança, incerteza, desconforto e mudança, propõe a reflexão sobre a aproximação entre a ideia de mudança e a de inovação, ainda que possuam significados distintos.

Nem sempre as mudanças presenciadas ou vivenciadas garantem um cenário de inovação, uma vez que esta é uma atitude de comprometimento com a prática, na perspectiva de melhoria planejada sistematicamente por um projeto, e é assim que deve ser compreendida e partilhada por todos, para que possa se tornar significativa.

Para que essas mudanças possam ser consideradas inovação, portanto, devem alterar as concepções centrais e materializar-se em resultados, devendo, para isso, ser incorporadas a um novo paradigma ou nova proposta, deparando-se com um conjunto de ações estabelecidas, que as respalde desde o próprio princípio epistemológico.

\section{Paradigma de formação em uma concepção inovadora}

De acordo com Claxton (2005), o professor do século XXI é um agente de socialização, e cabe a ele não somente transmitir conhecimentos mas, principalmente, valores morais e modos de vida que contribuam para que seus alunos encontrem condições de construir e reforçar a própria identidade, que, acima de tudo, é social. 
Entendemos que o papel de socialização desempenhado pelas instituições escolares e pelos professores esteve desvalorizado ao longo do período em que a racionalidade técnica era o centro das discussões acerca da Educação e da formação de professores, sendo que a identidade do indivíduo orientava-se por papéis predeterminados.

As análises e discussões sobre o professor tendem para um terreno mais racional e pragmático enquanto o mesmo não for considerado um ser humano permeado por experiências, histórias de vida e referências culturais.

Claxton (2005) sugere que, para lidar com as vicissitudes da vida e reagir a elas adequadamente, as pessoas veem a necessidade de não mais recorrer às fontes tradicionais de autoridade externa, mas trabalhar seu potencial de recursos internos.

Torna-se necessário que os sujeitos construam sua história pessoal e resgatem sua memória, suas realizações e escolhas de vida, os traços de personalidade que orientam sua ação, seus conhecimentos e opiniões.

0 autor defende, então, a necessidade de uma concepção de aprendizagem comprometida com o desenvolvimento do sentimento, da imaginação, da intuição e da experiência, reforçando a sugestão de García (1999) de se potencializarem as "teorias pessoais de aprendizagem". Na sociedade atual, as pessoas encontram meios para construírem a si mesmas e desenvolverem a própria inteligência, com o objetivo de potencializar o pensamento consciente, articulado e intencional.

Claxton (2005) considera que a inovação na Educação e na formação de professores compreende, sinteticamente, um conjunto de ações que decorre de uma prática política e intencional, estabelecida com o objetivo de produzir modificações e melhorias no contexto escolar, com vistas a atender às demandas de um grupo social frente às mudanças que se colocam no cenário mundial. Exige, portanto, ser entendida como um processo permanente e sistemático, planejado e não linear, considerando a cultura própria de cada estabelecimento de ensino, que determina a sua postura diante das mudanças.

A discussão sobre inovação exige que estejamos atentos para o novo momento no qual está inserida a comunidade global, marcada pela mudança na estrutura de pensamento que permeia 
o processo de construção do conhecimento, não mais centrado nos princípios e pressupostos do paradigma da ciência moderna herdada da filosofia positivista de mundo.

Diante de uma nova conjuntura mundial, caracterizada pelo avanço da ciência, da g'lobalização e da tecnologia da informação e comunicação, tornou-se insustentável para os sujeitos a compreensão da realidade à sua volta a partir de uma visão de mundo única, inquestionável e indiscutível, determinada pela ciência e pela razão.

A implicação desta tendência tecnicista para a vida dos sujeitos é negativa, contribuindo, de certo modo, para a formação de um ser com pouca disposição para o envolvimento e capacidade limitada para desenvolver seu potencial de reflexão e criação, já que, ainda segundo Claxton (2005), se desconsiderava o "trabalho de questionar o que era tacitamente aceito e de tomada de consciência do que era tácito".

A aquisição de um saber técnico e racional assumia importância maior do que a possibilidade do sujeito de vivenciar crenças, valores e estilos de vida diversificados, de modo que este encontrava dificuldades para trilhar o caminho de seu crescimento enquanto pessoa, consciente de sua missão política.

Diante dessa concepção, o significado do sujeito se definia a partir de tudo aquilo que ele produzia e apresentava no trabalho, apoiando-se, para isso, na tríade profissionalização/ especialização/produtividade, sem oportunidade de questionar a estrutura natural já estabelecida na sociedade.

Entretanto, presenciamos novos tempos. 0 conhecimento não é mais considerado algo estabelecido, acabado e inquestionável, de natureza exclusivamente técnica e científica. Os indivíduos que configuram a sociedade atual, por sua vez, mostram-se capazes de argumentar, questionar, ponderar, construir e avaliar as próprias experiências.

Este momento de mudança e incerteza, que configura o cenário político, econômico e social das nações, não se manifesta de forma indiferente à Educação, em geral, e mais particularmente à formação de professores.

A temática da inovação, particularmente na formação de professores, resulta de uma prática intencional, a partir da constatação de um problema, que deve comprometer-se com a perspectiva de uma melhoria planejada, compreendida e partilhada pelo coletivo. 
É preciso muito tempo e persistência para modificar práticas e atitudes e também para perceber seus resultados. As tarefas de pensar uma inovação, implementá-la e, principalmente, monitorála e avaliá-la é lenta e árdua.

Nas instituições de ensino, os projetos pedagógicos inovadores se fundamentam no paradigma de formação que contempla a construção de uma cultura com objetivos voltados para o pensamento crítico, não se limitando às aprendizagens acadêmicas, buscando-se, assim, a formação de um sujeito com sentido mais profundo do seu papel.

\section{Conclusão}

Este artigo partiu do pressuposto de que as questões da prática não se constituem problemas meramente instrumentais. Ao tratar da complexidade dos fenômenos educativos, encaminha-se para ultrapassar o modelo de formação baseado na racionalidade técnica, que forma o professor como especialista, considerando a formação mais complexa: a do cidadão, com compromisso político, com valores éticos e morais, que pressupõe o desenvolvimento da pessoa que seja capaz de conviver com as mudanças e a incerteza. Destaco o papel do professor como profissional que se confronta com situações singulares, tentando superar a relação linear e mecânica entre conhecimento científico e prática da sala de aula. Dessa forma, ao considerar os aspectos da complexidade da educação e da incerteza da relação entre formação de professores e mundo do trabalho, este artigo tem como base teórica a concepção da racionalidade prática, que considera a dimensão humana e a profissionalidade docente. Reflexão e ação tornam-se faces da mesma moeda.

Schön (1995), que tratou das reformas educacionais nos anos 80 , considera que o conceito de reflexão envolve conhecimentona-ação, reflexão-na-ação, sobre-a-ação e sobre-a-reflexãona-ação. Esses aspectos se complementam, constituindo o pensamento prático do professor, e garantem uma intervenção prática racional, partindo do pressuposto de que o professor, além de reflexivo, tem que ser propositivo e empreendedor. A reflexão é um conhecimento contaminado pela experiência do indivíduo. Propõe a formação do professor como prático reflexivo e aponta o ensino das artes, que considera o aprender fazendo, em que começam a praticar, mesmo antes de compreenderem racionalmente o que estão fazendo. No practicum reflexivo, os 
alunos-professores têm a oportunidade de refletir sobre a sua atuação, estabelecendo um diálogo com a situação complexa. Segundo Zeichner (1993), o practicum tem uma característica investigativa, que tem como ponto de partida a experiência dos alunos, preparando-os para entrar em comunidades de aprendizagem e não tanto para salas de aula isoladas.

Segundo Pérez Gómez (1995), o pensamento prático do professor é fundamental na formação do professor como profissional e não pode ser ensinado, mas pode ser aprendido na mediação do professor/supervisor. 0 professor enfrenta questões que exigem um tratamento ligado à sua história de vida e ao contexto.

Em relação ao desenvolvimento pessoal, Nóvoa (1995) trata da identidade do professor, dando um sentido às suas histórias de vida, destacando os saberes da experiência. A formação se constrói por meio de um trabalho de reflexão crítica sobre as práticas e de construção de uma identidade pessoal. Libâneo (2004), por sua vez, destaca que os saberes são conhecimentos teóricos e práticos da profissão e as competências são as capacidades, habilidades, atitudes relacionadas a esses saberes que permitem o exercício da profissão.

Segundo Canário (2006), a prática profissional, além de ser o elemento-chave do currículo de formação inicial de professores, é seu elemento estruturante, tendo como referência as situações de trabalho. Dessa forma, a estratégia formativa é a otimização do potencial nos contextos de trabalho, chamada de "formação centrada na escola". Passou-se da relação de previsibilidade entre formação de professores e mundo do trabalho para uma relação de incerteza, na racionalidade prática.

O pensamento de Nóvoa (1995) sobre a construção da identidade do professor ofereceu um eixo de análise no artigo, para sugerir elementos para a inovação na formação de professores.

A temática da inovação (Claxton, 2005), particularmente na formação de professores, resulta de uma prática intencional, a partir da constatação de um problema, que deve comprometerse com a perspectiva de uma melhoria planejada da prática, compreendida e partilhada pelo coletivo.

Por fim, dentre os pensadores que nortearam este artigo, Giroux (1997) aponta o papel dos educadores como intelectuais transformadores, combinando ação e reflexão para a formação dos alunos, para analisarem o mundo criticamente e transformá-lo. 
A formação docente é uma preparação para uma profissão complexa, já que o futuro professor deve reconhecer a incerteza da relação entre formação e mundo do trabalho e construir uma identidade do profissional no século XXI, tendo também como pressuposto o desenvolvimento pessoal autônomo, emancipatório, transformador em uma prática reflexiva.

\section{REFERÊNCIAS}

CANÁRIO, R. A escola tem futuro? Das promessas às incertezas. Artmed: Porto Alegre, 2006.

CLAXTON, G. O desafio de aprender ao longo da vida. Porto Alegre: Artmed, 2005.

FELDMANN, Marina Graziela et al. Formação docente e as mudanças na sala de aula: um diálogo complexo. In: Olhar de professor. Paraná: UEPG., 2004.

GARCÍA, C. M. Formação de professores: para uma mudança educativa. Porto: Porto Editora, 1999.

GIROUX, H. A. Os professores como intelectuais: rumo a uma pedagogia crítica da aprendizagem. Porto Alegre: Artmed, 1997.

LIBÂANEO, J. C. Organização e Gestão da Escola. Teoria e Prática. Goiânia: Alternativa, 2004.

MIZUKAMI, M. da G. N. et al. Escola e aprendizagem da docência: processos de investigação e formação. São Carlos: EduFSCar, INEP, 2003.

NÓVOA, A. Os professores e a sua formação. 2. ed. Lisboa: Instituto de Inovação Educacional, 1995.

PÉREZ-GÓMEZ, A. O pensamento prático do professor: a formação do professor como profissional reflexivo. In: NÓVOA, A. (org.). Os professores e a sua formação. 2. ed. Lisboa: Instituto de Inovação Educacional, 1995. p.95-114. 
SCHÖN, D. A. Formar professores como profissionais reflexivos. In: Nóvoa, A. (org.). Os professores e a sua formação. 2. ed. Lisboa: Instituto de Inovação Educacional, 1995. pp.79-91.

Educando o profissional reflexivo: um novo design para o ensino e a aprendizagem. Porto Alegre: Artmed, 2000.

The reflective practitioner: how professionals think in action. USA: Basic Books Inc, 1983.

ZEICHNER, K. M. El maestro como professional reflexivo em: Cuadernos de pedagogia, 220. Barcelona: Editorial Fontalba, 1993. 